\title{
Flow and particle distributions in a nearshore seagrass meadow before and after a storm
}

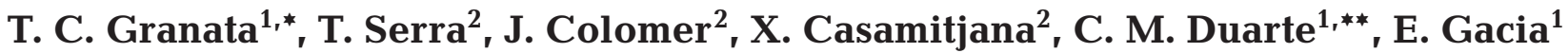 \\ ${ }^{1}$ Centre d'Estudis Avançats de Blanes, C. Santa Bàrbara s/n, 17300 Blanes (Girona), Spain \\ ${ }^{2}$ Environmental Physics, Department of Physics, University of Girona, Campus de Montilivi, 17071 Girona, Spain
}

\begin{abstract}
Fine-scale spatial effects of a seagrass meadow on suspended particle transport were assessed from current speeds, orbital wave velocities, turbulent Reynolds stress, in situ particle concentrations, and sedimentation rates for a horizontal grid in a coastal seagrass (Posidonia oceanica) meadow at 2 depths and during low- and high-energy periods. For the low-energy period, the vertical reduction of the total kinetic energy, from $100 \mathrm{~cm}$ to $\approx 10 \mathrm{~cm}$ above the bottom, was larger in the meadow (up to $95 \%$ ) than over the sand ( 35 to $75 \%$ ). Velocity maps suggest that a recirculating flow formed in the meadow with a higher Reynolds stress at the edge of the meadow. Near the bed, concentrations of small particles $(<10 \mu \mathrm{m}$ diameter) were lower inside the meadow than over barren sand, while concentrations of large particles $(>10 \mu \mathrm{m})$ were lower over the barren sand. For the period of stronger current and wave activity following a storm, nearbed turbulence and orbital wave velocity were elevated, though still lower inside the meadow than over the sand. For this high energy period, particle concentrations increased over the whole study area, but were still lowest deep inside the meadow. Overall, the horizontal spatial distribution of plants in the study area had a profound effect on the flow field and on vertical transport, even during the high-energy period. The reduced nearbed turbulence and lower sedimentation rate below the canopy confirms it as a calm zone with lower mixing compared to unvegetated areas.
\end{abstract}

KEY WORDS: Seagrass meadow $\cdot$ Flow fields $\cdot$ Particle transport

\section{INTRODUCTION}

In most shallow littoral zones, particle transport in the bottom boundary layer is dominated by wavecurrent interactions with bottom topography (Grant et al. 1984). In addition, changes in particle concentration depend on natural substrates described by shear strength, bed composition, pore-water content, and even the recent history of deposition and resuspension, especially in shallow wetlands (Nepf \& Oldham 1997), shallow lakes (Hawley \& Lesht 1997) and estuaries

Present addresses:

${ }^{*}$ Ecological Engineering Program, The Ohio State University, CEEGS 470 Hitchcock Hall 2070 Neil Avenue, Columbus, Ohio 43210-1275, USA. E-mail: granata@osu.edu

** Instituto Mediterraneo de Estudios Avanzados, C. Valldemossa km 7.5, 07071 Palma de Mallorca, Spain
(Wolanski et al. 1988). The development of the boundary layer has been extensively studied over rough bottoms, such as sand ripples and bioturbated sediments (Chriss \& Caldwell 1982, Grant et al. 1984, Gross et al. 1992), where a thicker boundary layer develops when the orbital wave speed exceeds mean current speed or the wave direction is aligned with currents (Grant \& Madsen 1979). In addition, simple substrates can generate 3-dimensional (3-D) structures in the flow (Lynch et al. 1997). Sparse data exist on the spatial effects of larger biological features, including reefs and seagrass meadows, and no data on their 3-D aspects.

Mixing and advection of suspended material in seagrass meadows are of particular importance because particles are part of a tightly coupled food web (Judge et al. 1993, Duarte et al. 1999) and because these processes may export seagrass production. The composition of particles in seagrass meadows is a complex of 
autotrophic and heterotrophic plankton, seagrass detritus, and sediments (Duarte et al. 1999). Filter feeders in and on seagrasses utilize suspended particles as food sources (Peterson et al. 1984, Irlandi \& Peterson 1991, Ambrose \& Irlandi 1992, Judge et al. 1993, Petersen et al. 1997), with the quality and quantity of these particles varying over time, depending on the flow conditions (Fegley et al. 1992). In addition to filter feeders, seagrasses provide habitats for fishes, invertebrates, and plankton, and are thought to stabilize sediments (Gleason et al. 1979, Fonseca \& Fisher 1986, Reusch \& Chapman 1995). Two ways in which they can stabilize sediments are by damping waves (Fonseca \& Cahalan 1992, Koch 1996, Verduin \& Backhaus 2000) and reducing currents (Fonseca et al. 1983, Gambi et al. 1990) below the canopies. While the above studies have show that flow over meadows, and its perturbation, have important ecological and environmental consequences, their interpretations have been based solely on 2-D sampling, either vertical profiles or single horizontal transects. What is still unclear is how the horizontal structure and finer spatial scales of plant distributions in meadows influence particle transport under different flow regimes.

Flow through and around seagrass meadows presents a unique situation, where individual plant elements can sway with the flow (Ackerman \& Okubo 1993, Grizzle et al. 1996), thereby reducing frictional drag. On the other hand, the transition from barren sand to dense plant cover at the edge of meadows may produce a bluff body effect, enhancing pressure (form) drag and flow acceleration/deceleration over the canopy. For bluff bodies on land such as hills, streamlines either accelerate over the hill or separate from the surface in a wake (recirculation) region. The net effect is an increased drag on the flow above the boundary layer and a distortion of the boundary layer near the surface (Belcher \& Hunt 1998). Unlike solid bluff bodies, however, meadows have void spaces between the plants where flow can penetrate into the canopy. The closest analogy might be flow through and over tree canopies and their effects on the atmospheric boundary layer (Oliver 1971, Shaw et al. 1974, Shaw 1977).

The horizontal spacing of the plants in a meadow creates a unique spatial pattern, especially at the edge of the meadow where it is an abrupt boundary to the flow. The spatial development of the thicker boundary layer over non-biological substrates is set up by the distribution and height of the roughness elements (Wooding et al. 1973, Rao et al. 1974). Similarly, it would be expected that the spatial characteristics of a meadow also produce flow modification where plant drag forms a thicker internal boundary layer over the canopy. So while the highest particle resuspension rates over unvegetated bottoms occur during energetic flow and wave events (Gross et al. 1992, Green et al. 1997, Lynch et al. 1997, Boon et al. 1998), the structure of meadows may reduce resuspension (Ward et al. 1984, Gacia et al. 1999) and transport into and out of the meadows.

In this study we have sampled a horizontal grid, with a $3 \mathrm{~m}$ resolution, to resolve horizontal and vertical transport processes in a meadow of the seagrass Posidonia oceanica. Based on high-resolution particle and flow data sampled over the grid, we test the hypotheses that: (1) particle transport is directly related to the horizontal structure of the meadow, and (2) the edge of the meadow is a boundary that acts as a bluff body to the flow field. Thus, we can assess if transport in the meadow is simply a vertical process, or if complex, 3-D physical-biological interactions dominate transport. The observations were conducted along an exposed coastline and captured the transition from quiescent seas to fully developed waves encompassing a storm event.

\section{METHODS}

The study site was a meadow of the seagrass Posidonia oceanica located at $15 \mathrm{~m}$ depth off Fenals Point, on the NE coast of Spain (NW Mediterranean Sea; Fig. 1). Four parallel transects, with 4 stations per transect, were arranged perpendicular to the edge of the meadow such that transects progressed from barren sand to the meadow's interior. Each station was $3 \mathrm{~m}$ from neighboring stations, forming a square $(4 \times 4)$ grid of 16 stations over an area of $81 \mathrm{~m}^{2}$. A large-scale bathymetric map of the study region was made from ship transects using GPS and sonar (Fig. 1b).

High-frequency $u$ (east-west), $v$ (north-south), and $w$ (vertical) velocity components were measured at 2 heights above the bottom (ab) at each station using 2 acoustic Doppler current meters mounted vertically inline on a stainless steel tripod. One Doppler current meter (Model ADV Laboratory, Nortek, Inc., Sandvika, Norway) was positioned at $100 \mathrm{~cm}$ ab and the second meter between 10 and $20 \mathrm{~cm}$ ab (Model ADV Oceans, SonTek, Inc., San Diego). At each station, a 5 min timeseries was collected at $25 \mathrm{~Hz}$ sampling frequency, after which the tripod was moved by divers to the next station of the grid. Tilt-and-compass angles were also recorded by the lower sensor and acoustic backscatter (amplitude) by both sensors. The resolution of Doppler measurements is $0.01 \mathrm{~cm} \mathrm{~s}^{-1}$, accurate to $0.4 \mathrm{~cm} \mathrm{~s}^{-1}$ for horizontal velocities and $0.1 \mathrm{~cm} \mathrm{~s}^{-1}$ for vertical velocities. Data were acquired in real-time via connections to portable computers aboard a ship at the surface, and divers signaled the beginning of the measurement series after repositioning the tripod. At the same time as the Doppler surveys, an in situ, laser particle-size 


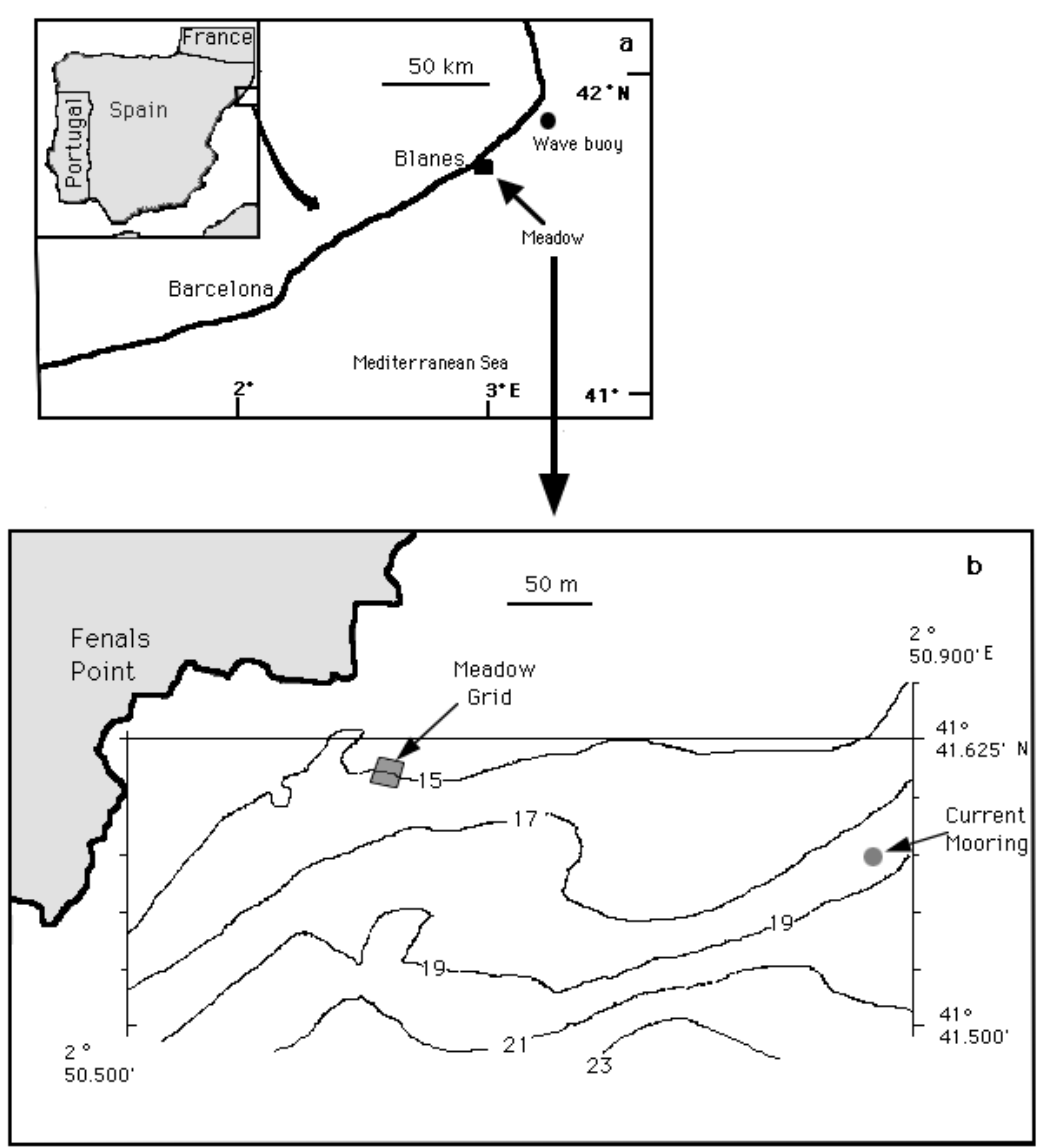

Fig. 1. Map of study site showing (a) location of Posidonia oceanica meadow on northeast coast of Spain, and (b) nearshore bathymetry (in m) off Fenals Point

pigments using HPLC (Schlüter \& Havskum 1997). At each station of the grid, canopy height and seagrass shoot density were measured in triplicate using standard procedures (Gacia et al. 1999). Profiles of temperature and salinity were measured after the Doppler surveys with a CTD (MeerestechnikElektronik, Trappenkamp, Germany).

To determine the temporal variations of the local horizontal flow during the Doppler surveys, an electromagnetic current meter (ACM8M, Alec Electronics, Tokyo) was deployed at a height of $100 \mathrm{~cm}$ above the barren sand, $6 \mathrm{~m}$ from the edge of the meadow between the 2 central transects. The ACM sampled the $u$ and $v$ velocity components at $2 \mathrm{~Hz}$ for the duration of the Doppler surveys. A meteorological station and a mooring with 3 current meters (Aanderaa) were located near the meadow and collected data every $10 \mathrm{~min}$ to characterize largerscale forcing. Errors in the Aanderaa meters and ACM were below 1 and $0.5 \mathrm{~cm} \mathrm{~s}^{-1}$, respectively. A wave gage, which was deployed near the current meter mooring, was damaged and returned no data during the meadow surveys. Therefore, time-series of significant wave height were obtained from a WaveRider buoy located $30 \mathrm{~km} \mathrm{NE}$ of Fenals Point, in $90 \mathrm{~m}$ of water off

analyzer (LISST-100, Sequoia, Inc., Redmond, WA) was placed at $10 \mathrm{~cm} \mathrm{ab}$, at the base of the Doppler array, to obtain a 4 min time-series of particle concentration and size at each station.

Synoptic Doppler and particle surveys were made at midday on 2 and 5 June 1998. The sampling on 2 June corresponded to a relatively calm energy period of low current and wave activity, which was followed by a series of storms from 4 to 6 June. Because of logistical and weather problems, not all stations could be sampled. On 2 June a $3 \times 3$ grid was sampled, and on 5 June the 2 central transects were sampled. From Days 2 to 5, sediment traps were placed at all 16 stations. Traps were deployed immediately after the Doppler survey on 2 June and recovered just before the second survey on 5 June. The sediment traps were the same design as that used by Gacia et al. (1999) and were located $15 \mathrm{~cm}$ above the bottom. In the laboratory, sedimented material was filtered through $25 \mathrm{~mm}$ GF/F filters and analyzed for dry weight by drying for $24 \mathrm{~h}$ at $60^{\circ} \mathrm{C}$. Water samples inside and outside the meadow $(\approx 10 \mathrm{~cm} \mathrm{ab})$ were analysed for a suite of plant
Palamós, Spain. The surface buoy sampled at a frequency of $2 \mathrm{~Hz}$, with data averaged to $1 \mathrm{~h}$ time bins.

After removing spikes from the Doppler time-series, instantaneous velocities were rotated parallel and perpendicular to the meadow edge. Time-series were averaged over $5 \mathrm{~min}$ to determine mean velocities and current direction. Turbulent Reynolds stress was calculated by de-meaning the time-series, removing the wave signal with a bandpass filter, and applying geometric corrections for the $x-y-z$ coordinates using calibration matrices provided with the Doppler probes (Lohrmann et al. 1995). Physical and biological parameters were mapped by a krigging technique to elucidate the spatial distributions in the meadow. Orbital wave velocity $\left(u_{\mathrm{b}}\right)$ was calculated as

$$
u_{\mathrm{b}}=2^{1 / 2} u_{\mathrm{rms}} \cos \left(2 \pi f_{\mathrm{p}} t\right)
$$

(Boon et al. 1998). $u_{\text {rms }}$ (root mean square) was calculated every $2.5 \mathrm{~s}$ for a $18 \mathrm{~s}$ window (i.e. a moving window) along the $5 \mathrm{~min}$ time-series which averaged roughly 4 to 6 wave cycles in each ensemble. The principal wave frequency, $f_{\mathrm{p}}$, for these monochromatic 
Table 1. Summary of flow conditions at the study site including wind speed, significant wave height $\left(H_{1 / 3}\right)$, mean wave period, principal wave direction $\left(\theta_{\mathrm{w}}\right)$, mean current speed measured $10 \mathrm{~m}$ above bottom (U[10 m]), and mean current direction $\left(\theta_{\mathrm{c}}\right)$. Temporal means were calculated over the duration of the meadow (Posidonia oceanica) surveys during low-energy event on 2 June and highenergy event on 5 June. $U[10 \mathrm{~m}]$ is the temporal mean of the topmost Aanderaa current meter

\begin{tabular}{|lcccccc|}
\hline Day & $\begin{array}{c}\text { Wind speed } \\
\left(\mathrm{m} \mathrm{s}^{-1}\right)\end{array}$ & $\begin{array}{c}H_{1 / 3} \\
(\mathrm{~cm})\end{array}$ & $\begin{array}{c}\text { Wave period } \\
(\mathrm{s})\end{array}$ & $\begin{array}{c}\theta_{\mathrm{w}} \\
(\text { degrees })\end{array}$ & $\begin{array}{c}U[10 \mathrm{~m}] \\
\left(\mathrm{cm} \mathrm{s}^{-1}\right)\end{array}$ & $\begin{array}{c}\theta_{\mathrm{c}} \\
(\text { degrees })\end{array}$ \\
\hline 2 June & 3 & 41 & 3.0 & 2 & 6 & 204 \\
5 June & 13 & 96 & 4.3 & 331 & 17 & 59 \\
\hline
\end{tabular}
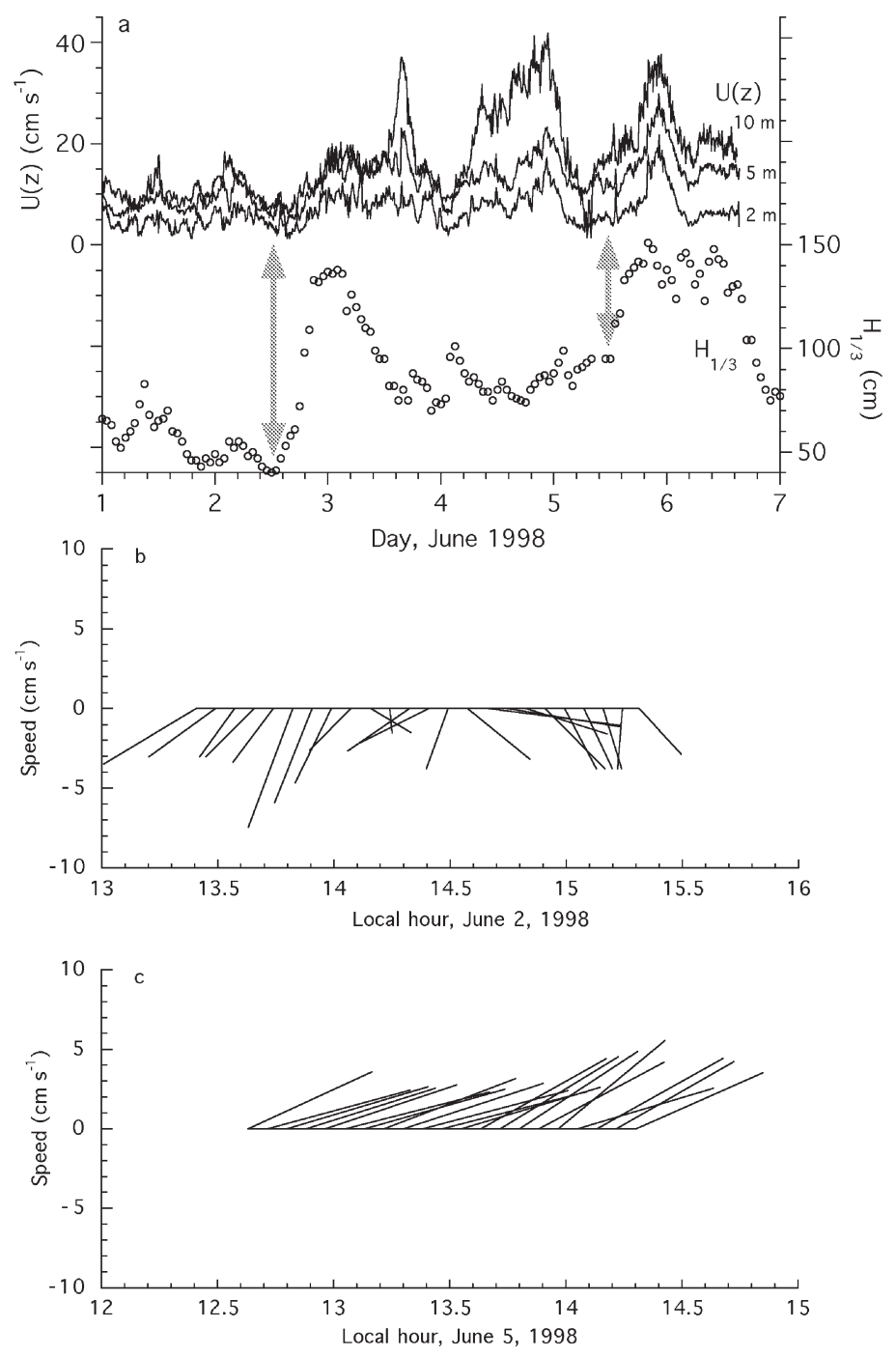

Fig. 2. (a) Time-series (1 to 6 June 1998) of significant wave height $\left(H_{1 / 3}\right)$ from Palamós and mean current speeds over depth $u(z)$ for the Aanderaa current mooring; (b) velocity vectors outside the Posidonia oceanica meadow during survey on 2 June; (c) velocity vectors during the meadow survey on 5 June. Vectors are $10 \mathrm{~min}$ averages from ACM8M current meter located $100 \mathrm{~cm}$ above the sand bottom waves was determined from the peak in the power spectra of the vertical $(w)$ velocity component, $S_{w w}$. First, timeseries were de-meaned and de-trended (linearly), padded with zeros to 8092 points, and a $25 \%$ taper was applied. Power spectral densities were then calculated from Fast Fourier Transforms algorithms using MatLab subroutines for data windowed to 256 points with a Hamming weighting. Mean wave direction was calculated from auto and cross spectra of the $u, v, w$ components (Nagata 1964).

\section{RESULTS}

\section{Temporal variations}

During the first week of June 1998, wind speeds, current speeds, and wave heights increased as current and wave directions shifted during the passage of a storm front (Table 1). From the morning of 1 June to the evening of 2 June, significant wave height (mean one-third of highest wave amplitudes) was $<50 \mathrm{~cm}$ and current speeds were low, with a mean value of $6 \mathrm{~cm} \mathrm{~s}^{-1}$ at $10 \mathrm{~m}$ above the bottom and $<5 \mathrm{~cm} \mathrm{~s}^{-1}$ near the bottom (Fig. 2a). By 3 June, wave height and current speeds had increased, with episodic peaks of $140 \mathrm{~cm}$

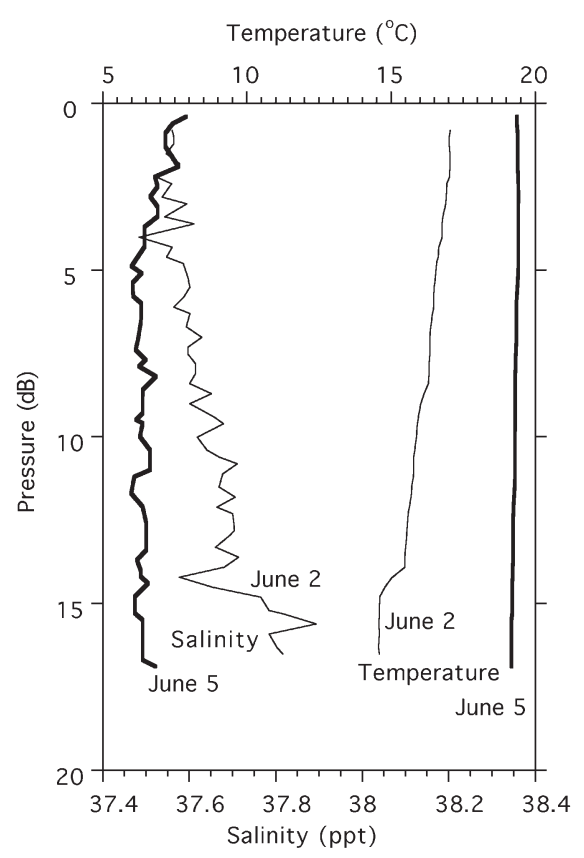

Fig. 3. Vertical distributions of temperature and salinity sampled by CTD casts at midday on 2 and 5 June 1998 
and $35 \mathrm{~cm} \mathrm{~s}^{-1}$, respectively. The effect of the storm was manifested in the overall higher energy levels for the remainder of the observational period. During the first survey of the Posidonia oceanica meadow on 2 June, low current speeds over the sand bed varied in time, but were generally oriented to the SW-SE, nearly perpendicular to the edge of the meadow and parallel to the coast (Fig. 2b). Wave heights of $40 \mathrm{~cm}$ were at their lowest for the entire observational period (Fig. 2a), and waves were oriented $>90^{\circ}$ to the mean current (Table 1 ). Three days later (midday on 5 June), significant wave height had reached $96 \mathrm{~cm}$ (Fig. 2a, Table 1) and current speeds had tripled (Fig. 2c). Current direction reversed with flow out of the meadow and up the coast, and waves were angled $\approx 90^{\circ}$ to the direction of the mean current (Table 1). There was temperature and salinity stratification on 2 June, but the water column was completely mixed on 5 June following an increase in temperature and a decrease in salinity (Fig. 3).

\section{Spatial patterns}

Plant density and height were not homogeneous over the grid, as can be seen from maps of the survey on 2 June (Fig. 4). There was a general increase in seagrass density from the edge of the meadow, except for an area of lower plant density which extended diagonally across the center of the grid (from $x, y$ grid coordinates 3,0 to $6,-3$ ) and which appears as a density gap in the maps (Fig. 4a). Hereafter, this area of low plant density will be referred to as 'the gap'. Current vectors for the ACM (electromagnetic current meter) were less variable over time than the current vectors over the survey area, indicating that the topography (i.e. seagrass distribution) dominated the flow dynamics over the grid (Fig. 4b,c). Before the storm, 2 regions were distinguishable: (1) a region above the canopy $(100 \mathrm{~cm} \mathrm{ab})$ where the current traveled eastwards, as did the flow outside the meadow (Fig. 4b); and (2) a region in the northeast grid with a current in the opposite direction. These opposing flows created horizontal shear above the meadow gap. After the storm, velocities in the study area were elevated, less variable in speed and direction, and generally directed out of the meadow (Fig. 4c).

The spatial distribution of the total kinetic energy, KE $\left(\mathrm{KE}=1 / 2\left[u^{2}+v^{2}+w^{2}\right]\right)$ at $100 \mathrm{~cm}$ ab during the first survey showed a horizontal gradient with maximum values over the meadow gap (Fig. 5a). Nearbed KE was lower

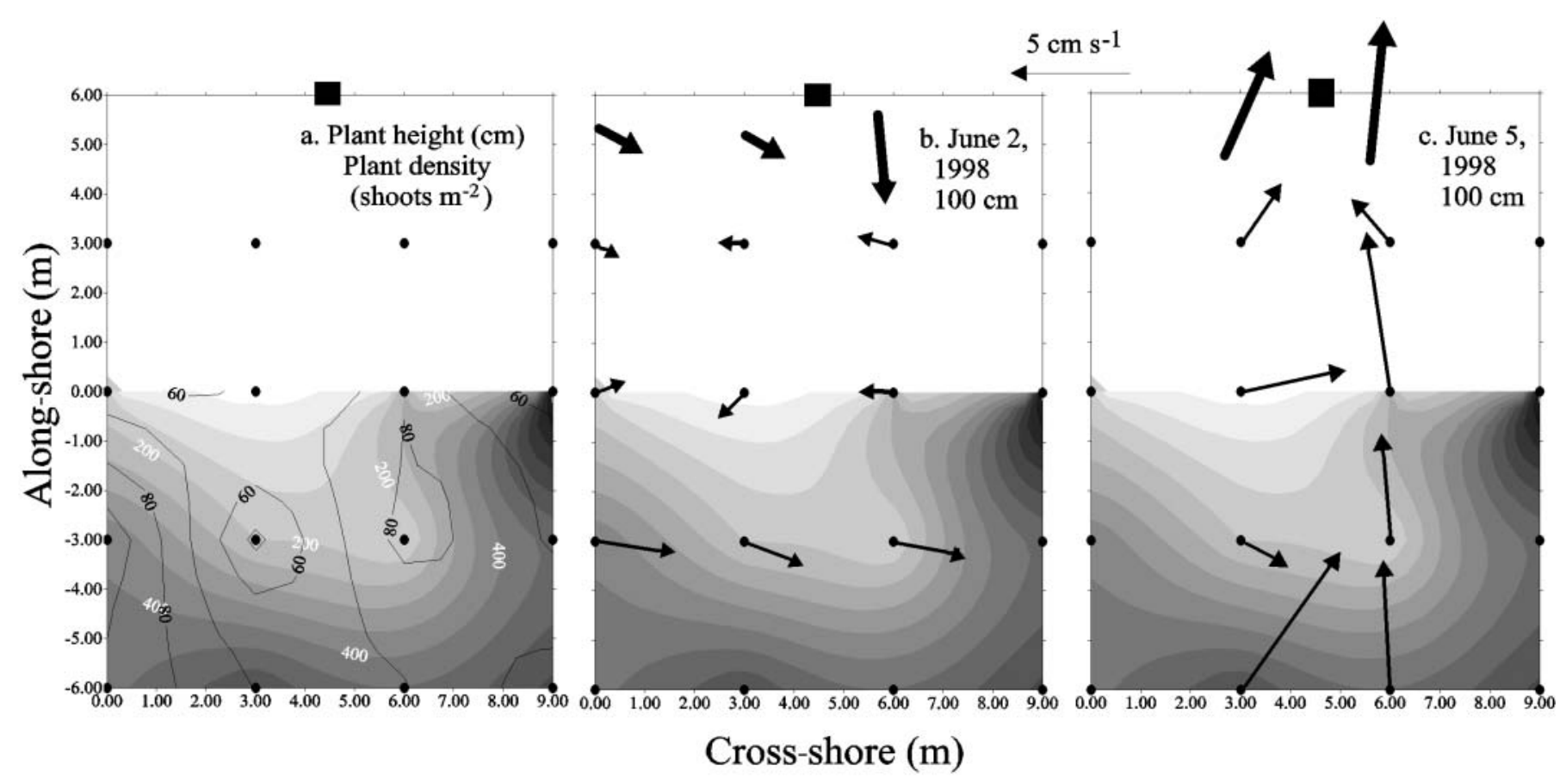

Fig. 4. Posidonia oceanica maps of meadow grid, where vertical axis is parallel to the shoreline (alongshore) with negative distances $(\mathrm{m})$ into the meadow and positive values over sand. (a) Spatial distribution of plant height (lines) and plant density (shading). (b,c) Plant density and horizontal current vectors above the canopy on 2 and 5 June, respectively. Thin velocity vectors (thin arrows): means derived from the ADV-meters time-series (Doppler survey) measured $100 \mathrm{~cm}$ above the meadow bottom; thick velocity vectors (bold arrows): means from the ACM8M current meter located $100 \mathrm{~cm}$ above the sand bottom ( $\square$ ), averaged for the duration of each transect (Doppler survey) measurement, and thus representing changes in local currents during the mapping of a transect. Scale vector of $5 \mathrm{~cm} \mathrm{~s}^{-1}$ is shown at the top of (b) and (c) 


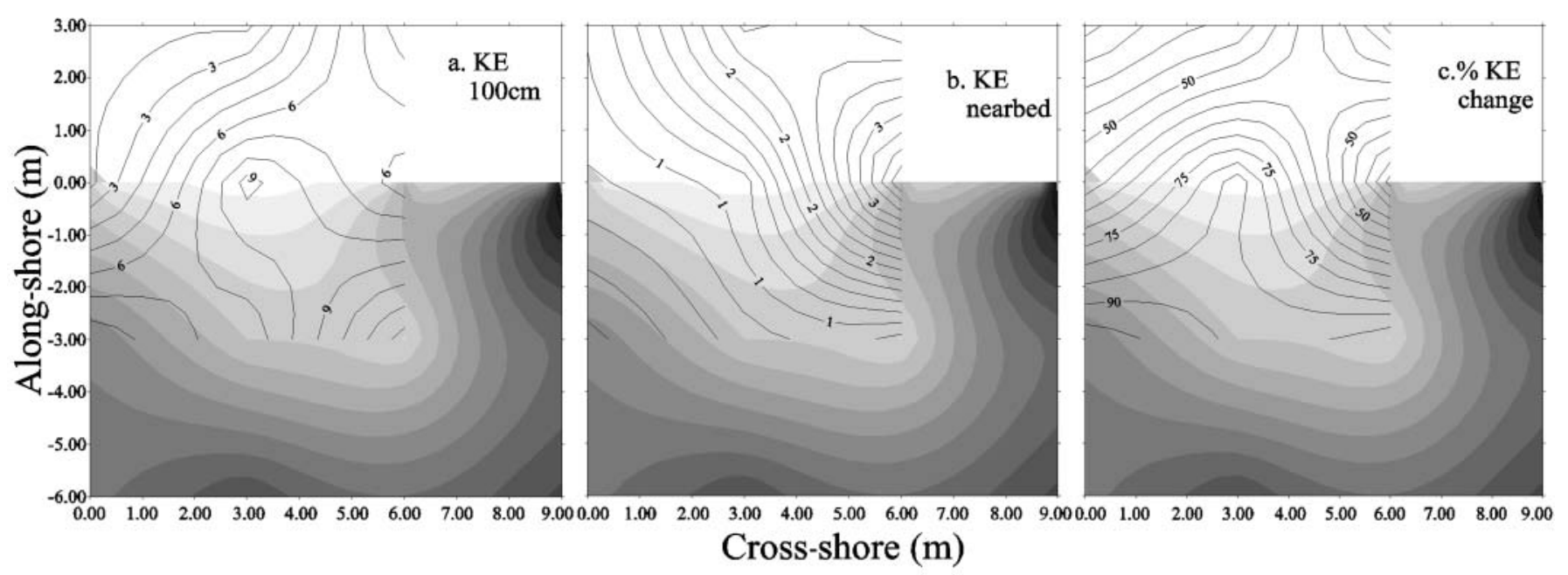

Fig. 5. Contour map of mean total kinetic energy, KE $\left(\mathrm{cm}^{2} \mathrm{~s}^{-2}\right)$, on 2 June. (a) KE measured at $100 \mathrm{~cm}$ above bottom; (b) nearbed $\mathrm{KE}_{i}$ (c) \% change of KE near the bed. Shading: Posidonia oceanica densities (shoots $\mathrm{m}^{-2}$ ) as in Fig. 4. \% KE change: ratio between nearbed KE and KE at $100 \mathrm{~cm}$ above bottom, representing a reduction of momentum by the plants and other bedforms

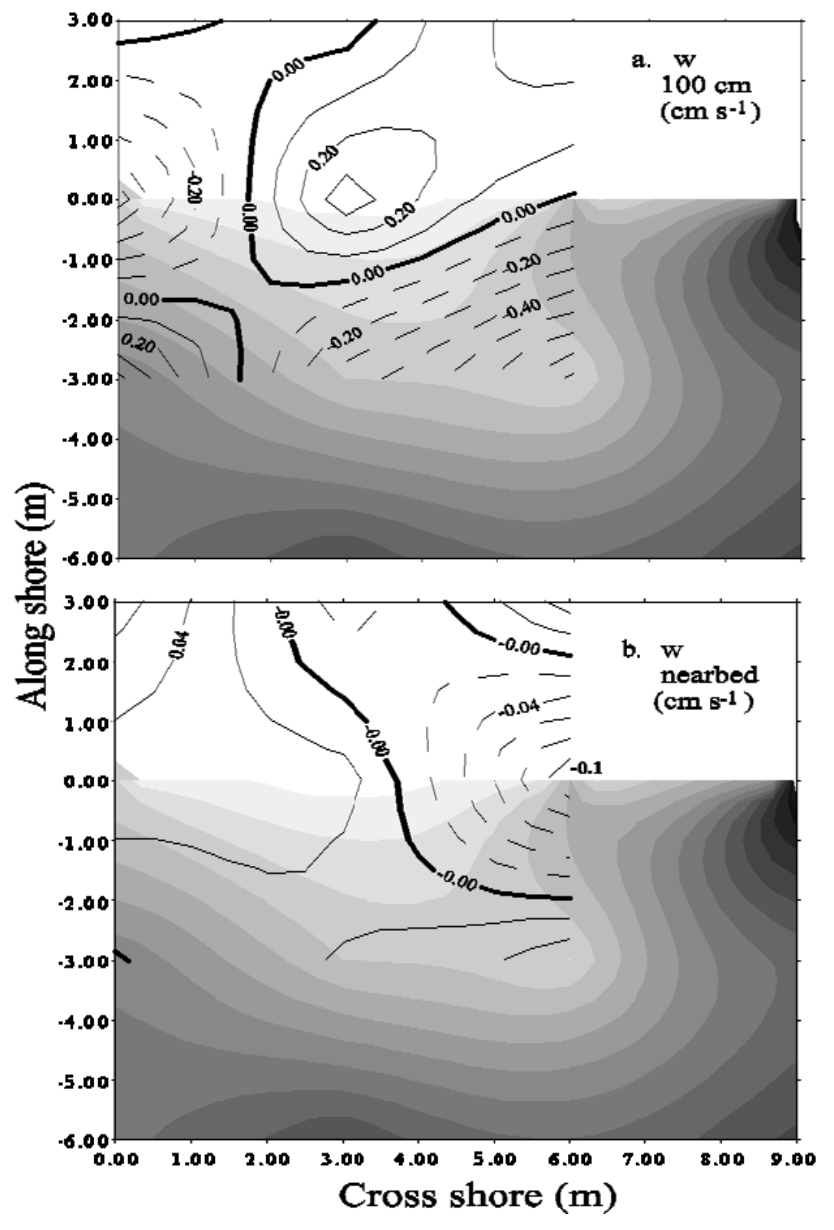

Fig. 6. Contour map of mean vertical velocities, $w\left(\mathrm{~cm} \mathrm{~s}^{-1}\right)$, on 2 June measured by the 2 ADV current meters. (a) $w$ measured at $100 \mathrm{~cm}$ above bottom; (b) nearbed $w$. Positive vertical velocities (solid lines) are upward and negative velocities (dotted lines) are downward than at $100 \mathrm{~cm}$ ab, with lines of equal values of KE protruding into the gap (Fig. $5 \mathrm{~b}$ ). Up to a $95 \%$ reduction in KE occurred from the top of the canopy to near the bed, compared to a $<50 \%$ reduction for the same vertical distance over the barren sand (Fig. 5c), showing that plants were very efficient at reducing the energy of the flow.

Mean vertical velocities were low but within the error of the sensors. At $100 \mathrm{~cm}$ ab, the highest upward (positive) flow was over sand, near the edge of the meadow, and the highest downward motion was at the head of the gap (Fig. 6a). These upward and downward motions corresponded to the region of horizontal shear (Fig. 4b) and increasing KE (Fig. 5a) in the meadow gap. Mean, nearbed vertical velocities were as high as $-0.1 \mathrm{~cm} \mathrm{~s}^{-1}$ (downward), with near-zero velocities aligned with the meadow gap (Fig. 6b). These observations suggest the existence of a complicated circulation at the boundary of the seagrass meadow, as expected for a flow encountering a bluff body.

Mean vertical fluid transport at $100 \mathrm{~cm} \mathrm{ab}$, represented by the turbulent Reynolds stress $\left(u^{\prime} w^{\prime}\right)$, had a local maximum at the top of the canopy near the edge of the meadow and decreased radially outwards (Fig. 7a). Over the barren sand, values of turbulent Reynolds stress near the bed (Fig. 7b) were slightly higher than those at $100 \mathrm{~cm} \mathrm{ab}$. Orbital wave velocity $\left(u_{\mathrm{b}}\right)$ at $100 \mathrm{~cm}$ $\mathrm{ab}$ were lower over sand than over the canopy (Fig. $7 \mathrm{C}$ ). Near the bed, both mean Reynolds stress and orbital wave velocity were lowest in the meadow and progressively increased with decreasing plant density.

Particles larger than $10 \mu \mathrm{m}$ (spherical diameter) were less concentrated in the gap and more concentrated inside the meadow (Fig. 8a), coincident with the area of low KE (Fig. 5b) and Reynolds stress (Fig. 7b). In contrast, nearbed particles smaller than $10 \mu \mathrm{m}$ were 

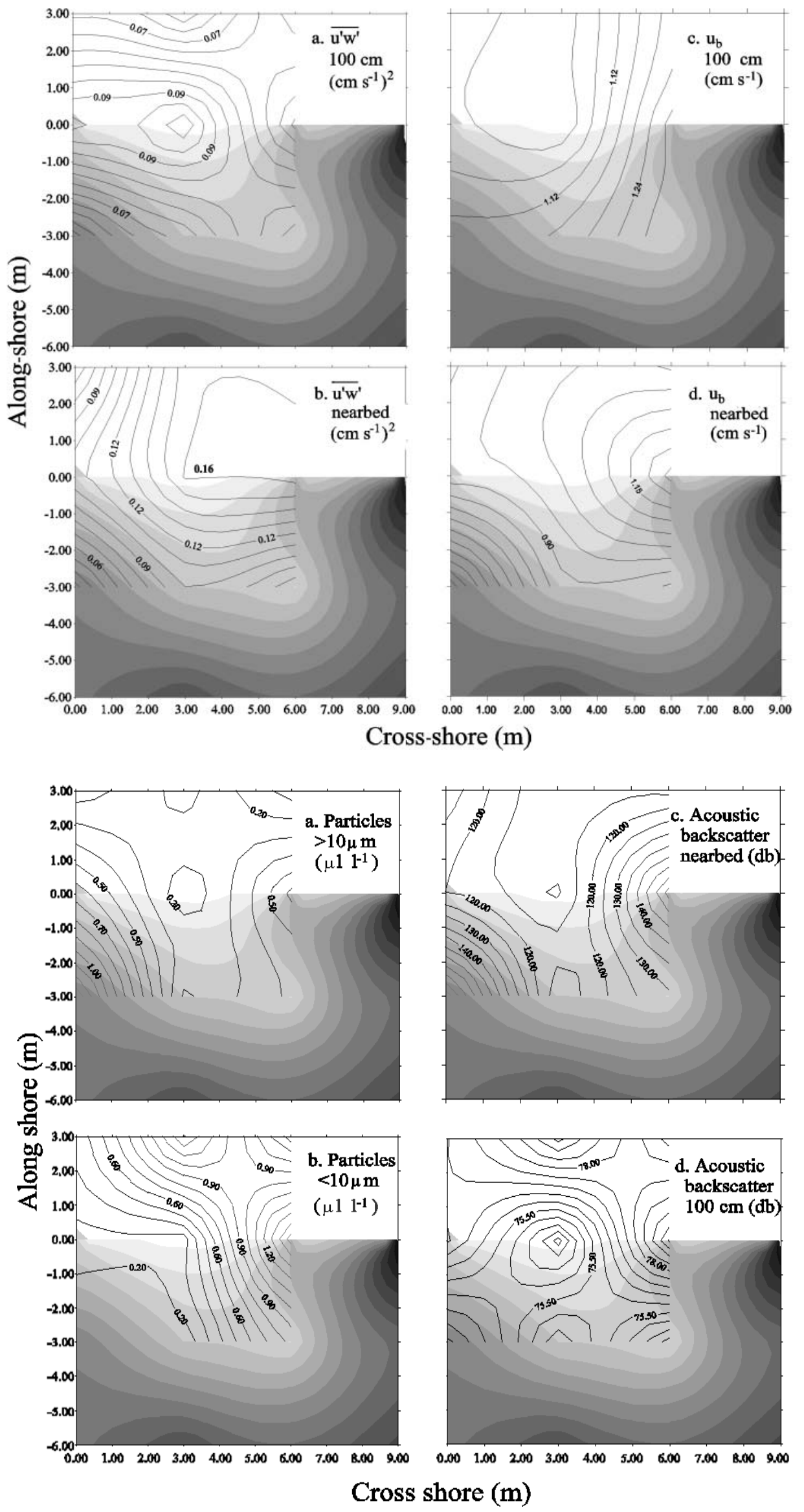

Fig. 7. Contour maps of mean Reynolds stress $\left(u^{\prime} w^{\prime}\right)$ and mean orbital wave velocity $\left(u_{b}\right)$ on 2 June. (a) Reynolds stress measured at $100 \mathrm{~cm}$ above bottom; (b) nearbed Reynolds stress; (c) orbital wave velocity at $100 \mathrm{~cm}$ above bottom; (d) nearbed orbital wave velocity. Reynolds stress represents the vertical transport component for particles, while orbital wave velocity is the speed associated with closed wave orbitals. High Reynolds stress and wave velocity usually lead to resuspension of sediments

Fig. 8. Contour map of in situ particle concentrations from the LISST sensor and acoustic backscatter from the ADV current meters on 2 June. (a) concentration of large $(>10 \mu \mathrm{m}$ spherical diameter) nearbed particles; (b) concentration of small $(<10 \mu \mathrm{m}$ spherical diameter) nearbed particles; (c) nearbed acoustic backscatter; (d) acoustic backscatter at $100 \mathrm{~cm}$ above bottom 

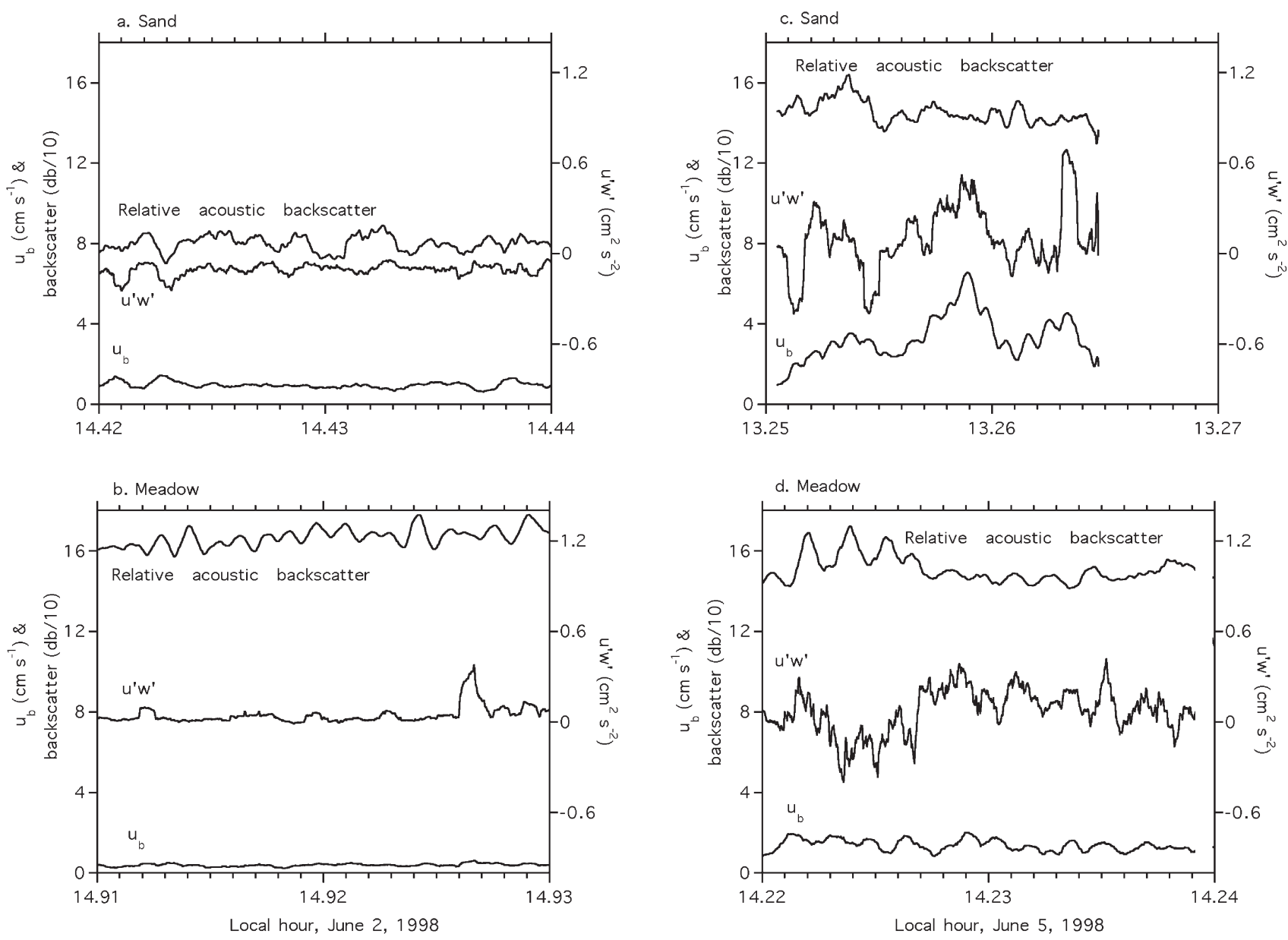

Fig. 9. Time-series of nearbed stress $\left(u^{\prime} w^{\prime}\right)$, orbital wave velocity $\left(u_{\mathrm{b}}\right)$, and relative acoustic backscatter on 2 June for (a) sand and (b) Posidonia oceanica meadow and on 5 June for (c) sand and (d) meadow. Note the higher values and fluctuations during the storm event on 5 June

more concentrated over the barren sand and at the edge of the meadow (Fig. 8b), coincident with region of high KE (Fig. 5b) and Reynolds stress (Fig. 7b). The pattern of the acoustic backscatter near the bed, which is a function of particle size and concentration as well as particle density, closely resembled the concentration pattern for the large particles (Fig. 8c). Acoustic backscatter at $100 \mathrm{~cm}$ ab was nearly half nearbed values, and was highest at the meadow's edge, where vertical fluid transport was also highest (Fig. 8d).

\section{Temporal-spatial variability: low-energy versus high-energy days}

The time-series of nearbed, relative acoustic backscatter (here used to characterize particle fluctuations), $u^{\prime} w^{\prime}$, and $u_{\mathrm{b}}$ for sand stations and meadow stations with maximal plant densities $\left(>375\right.$ shoots $\mathrm{m}^{-2}$ ) illustrate the temporal variability of particles and transport outside and inside the meadow. Peaks in Reynolds stress and orbital wave velocities often coincided. Fluctuations in the relative acoustic signal were inversely related to these 2 parameters, which is probably a result of particles being suspended out of the sensor volume and settling back into the sensor's pathlength. During the period of low-energy on 2 June, the level of the relative backscatter was lower over sand than in the meadow while $u^{\prime} w^{\prime}$ and $u_{b}$ were slightly higher over sand (Fig. 9a,b). During the high-energy period, the level of the relative backscatter was much higher than during the low-energy period, but similar to the level in the meadow (Fig. 9c,d). For both periods, fluctuations in $u^{\prime} w^{\prime}$ and $u_{b}$ were higher over barren sand than inside the meadow. Further, mean turbulence was reduced by 53 and $30 \%$ for the low- and high-energy periods, respectively, and mean orbital wave velocities were reduced by 57 and $75 \%$, respectively. This suggests that 
turbulence is reduced inside the meadow and that waves are attenuated below the seagrass canopy.

\section{Particle distributions}

Size distributions of nearbed particles over sand and at the head of the meadow gap were tri-modal, with peaks centered on the $<2,4$ to 7 and $>10 \mu \mathrm{m}$ size bins (Fig. 10). For the lower-energy period, concentrations were highest over sand in the $<2$ and 4 to $7 \mu \mathrm{m}$ diameter bands, with a nearly 5 -fold smaller peak centered over the $20 \mu \mathrm{m}$ diameter band. Inside the meadow, particle concentrations were low, with minor peaks around the 9 and $50 \mu \mathrm{m}$ (Fig. 10) bands. During the high-energy period, the highest particle concentrations were in the largest size classes for both the sand and the gap (Fig. 10). Particle concentrations in the $<2 \mu \mathrm{m}$ and the 4 to $7 \mu \mathrm{m}$ diameter bands in the meadow on 5 June approached the values over sand on 2 June; however, values over sand during the highenergy period were 1.5- to 2-fold more concentrated. During the high-energy period, particles included a mix of pigments that had nearly equal concentrations inside and outside the meadow (Table 2).

The overall affect of the distribution of plants on the flow and particle fields is more clearly represented in Fig. 11. Despite the higher mean KE on Day 5 compared to Day 2, the energy of the flow decreased with increasing plant density (Fig. 11a). This same pattern occurred for the small particles $(<10 \mu \mathrm{m})$, where concentrations were $5 \times$ to $10 \times$ higher on Day 5 than on Day 2 (Fig. $11 \mathrm{~b}$ ). Concentrations of large particles $(>10 \mu \mathrm{m})$ increased more than $125 \%$ from Days 2 to 5 (Fig. 11c). Unlike the smaller particles, large particles had higher concentrations in the meadow for the low-energy event, while during the high-energy period concentrations in the meadow were lower, except for a local high in the gap (Fig. 11c).

Table 2. HPLC pigment concentrations $\left(\mu \mathrm{g}^{-1}\right)$ for nearbed water samples obtained midday, 5 June 1998. chl: chlorophyll; fuc: fucoxanthin; diadinox: diadinoxanthin

\begin{tabular}{|lccccc|}
\hline Location & \multicolumn{5}{c|}{ Pigments } \\
\hline & $\underline{\text { chl } a}$ & $\underline{\text { chl } b}$ & $\underline{\text { chl } c}$ & peridinin & $\underline{\beta \text {-carotene }}$ \\
Edge & 0.267 & 0.016 & 0.033 & 0.008 & 0.042 \\
Meadow & 0.372 & 0.018 & 0.043 & 0.012 & 0.071 \\
Sand & 0.301 & 0.024 & 0.034 & 0.009 & 0.057 \\
& & & & & \\
Edge & $\underline{\text { fuc }}$ & $\underline{19-h e x-f u c}$ & $\underline{19-b u t-f u c}$ & $\underline{\text { diadinox }}$ \\
Meadow & 0.085 & 0.084 & 0.018 & 0.060 \\
Sand & 0.054 & 0.104 & 0.000 & 0.032 \\
& & 0.081 & 0.016 & 0.025 \\
\hline
\end{tabular}

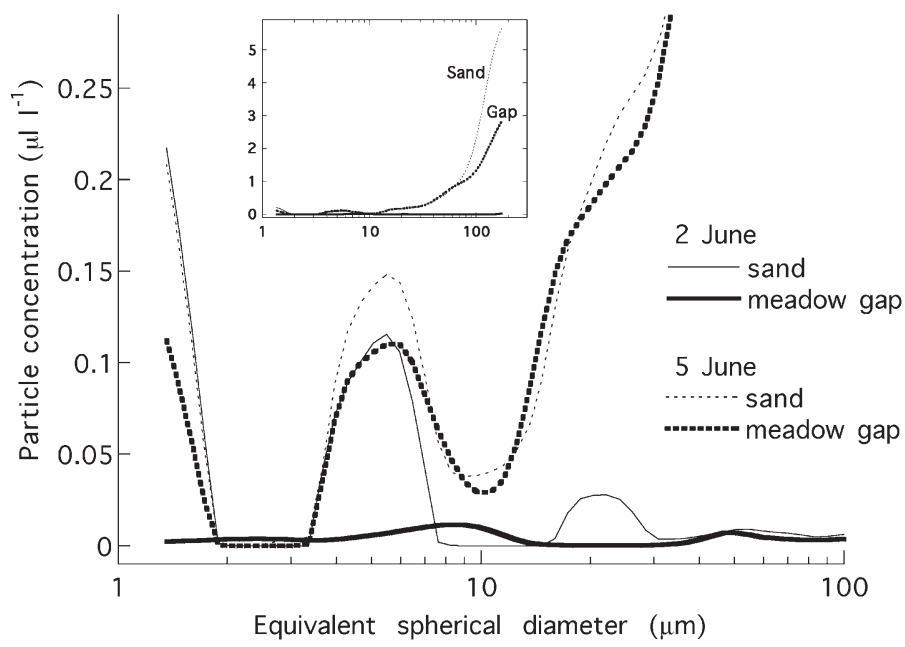

Fig. 10. Size distribution (equivalent spherical diameter) of volume concentrations for nearbed particles over sand and in the Posidonia oceanica meadow gap on Days 2 and 5. Inset shows the complete in situ size spectrum. Note the increased load for the largest particle classes during the storm event on 5 June

\section{Sedimentation of particulate matter}

The sediment traps deployed in the meadow provided a map of total deposition over the grid from Days 2 to 5 . A gradient of decreasing deposition existed inside the meadow and was inversely proportional to the distribution of shoot densities within the meadow (Fig. 12). The lower deposition in the meadow was a result of lower resuspension estimated from profiles of sediment trap fluxes (not shown). Lower resuspension is also reflected in the particle concentrations in the meadow (Fig. 11b,c) which presumably were reduced as a result of lower vertical perturbations of $u^{\prime} w^{\prime}$ and $u_{\mathrm{b}}$ in the meadow.

\section{DISCUSSION}

The low wave activity and a moderate current (i.e. low energy) moving down the coast, coincident with the vertical density stratification on 2 June, are very characteristic of flow and fluid conditions along this coastline. For this relatively calm period, orbital wave and current velocities outside the Posidonia oceanica meadow were low. The flow reversal on 5 June, with currents moving up the coast (NE) and waves to the NW, represented episodic physical forcing driven by high waves and current shears. The higher temperature and lower salinity for the high-energy period signify a change in water mass that was advected over the site.

Concentrations of small particles $(<10 \mu \mathrm{m})$ on both days were consistently highest over the unvegetated sand areas, decreased inside the meadow, and were a 
direct effect of the lower fluid transport with increasing amounts of vegetation. The reduced nearbed turbulence below the canopy confirms observations of lower mixing in meadows (Ackerman \& Okubo 1993, Nepf et al. 1997) and therefore points to higher residence times for particles below canopies of aquatic plants (Eckman et al. 1989). During the high-energy period, the
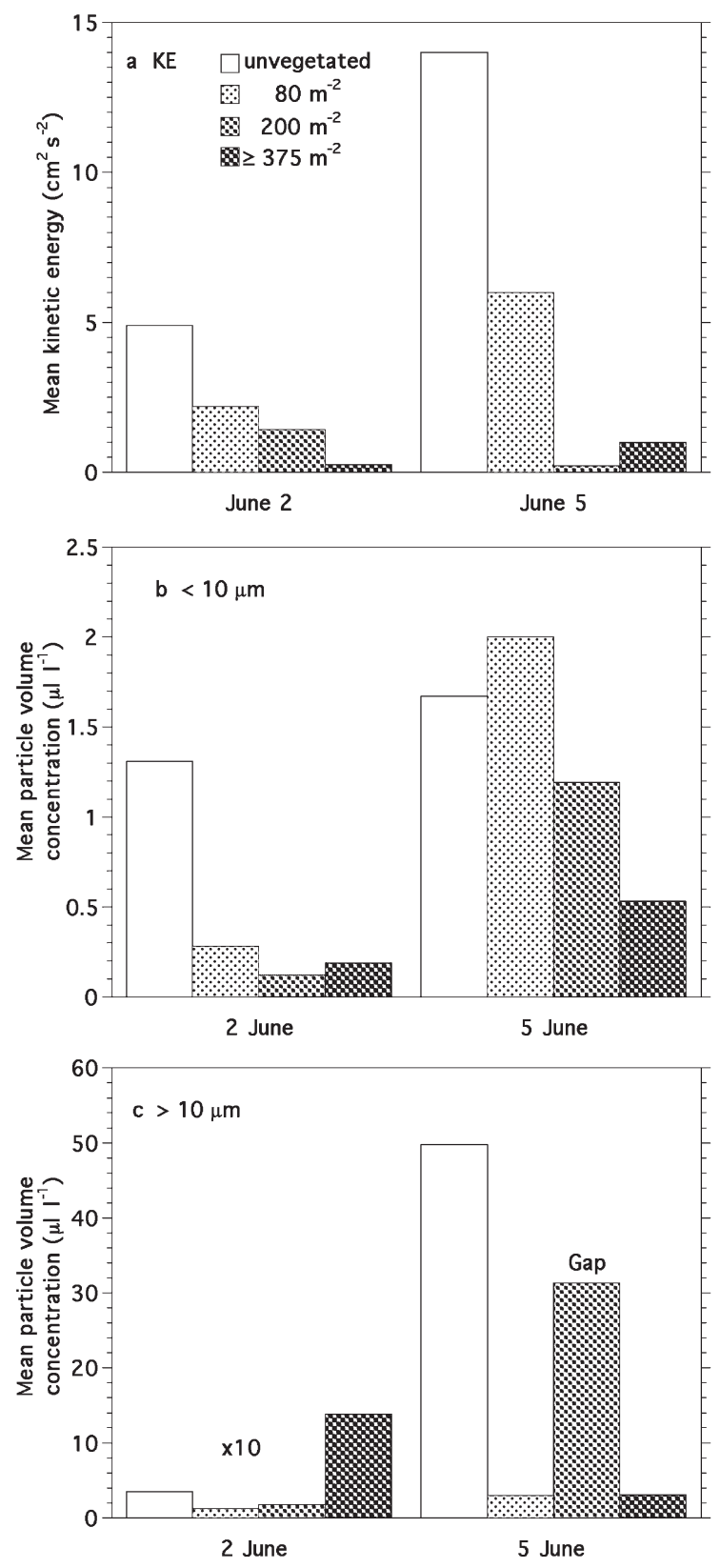

Fig. 11. Mean kinetic energy and particle concentrations as a function of Posidonia oceanica shoot density for surveys on Days 2 and 5. (a) Kinetic energy; (b) particle concentrations for small particles; (c) particle concentrations for large particles (note that $10 \times$ scale change for 2 June was necessary to depict the low concentrations of particles detected) meadow seemed to be dominated not only by vertical transport, which elevated nearbed particle concentrations, but also by horizontal advection, which homogenized pigment and particle distributions between the sand and the gap. Low values of nearbed particle concentrations in the denser stand of the meadow, even after the storm event, reflect low particle resuspension by turbulence and wave processes. This is corroborated by the low sedimentation rates in the meadow, where sediment traps integrated the effects of calm and storm conditions. The lower resuspension of nearbed particles in the meadow compared to the barren sand area confirms the importance of seagrass coverage in promoting sediment stability (Gacia et al. 1999).

Maps of particles show that the concentration of small particles was greater over the barren sand area when turbulence was highest. These small particles were probably dense bottom sediments that were kept in suspension by the turbulence. In contrast, concentrations of large particles were greater in the meadow during the calm period when total energy was lowest. It is likely that these large particles were lighter (i.e. less dense) plant detritus which could be kept in suspension by relatively low turbulence and wave motions. Moderate levels of chlorophylls $b$ and $c$ and accessory pigments indicate that fragments of Posidonia oceanica leaves were the major contributor to the distribution of the larger particles, which would be consistent with similar observations from other $P$. oceanica meadows (Dauby et al. 1995). Past studies of particulate material over vegetated substrates did not discriminate the size of particles, but simply reported total suspended concentrations (Ward et al. 1984, Leonard \& Luther 1995). Our fine-scale observations stress the importance of vertical-horizontal coupling for the transport of different-sized particles in meadows.

Maps of flow and plant distributions show that the meadow acts as a bluff body, modifying the flow pattern during low-energy conditions and causing turbulence at the meadow edge. The increase in current speeds over the meadow canopy, the upward motions at the edge of the canopy, and the downward motions at the head of the gap all indicate a recirculating flow formed in the gap. Current, turbulent and wave fields were modifications by the spatial distribution of the individual plants in the meadow linking 3-D spatial patterns to boundary-layer modifications. While other studies have found that mean flow (Fonseca et al. 1983, Gambi et al. 1990), turbulence (Gambi et al. 1990, Koch 1996) and wave (Grizzle et al. 1996, Koch 1999) processes modify the 2-D boundary layer in meadows, this is the first study to look at the horizontal scales in detail. The 3-D data suggest that the fine-scale spatial 


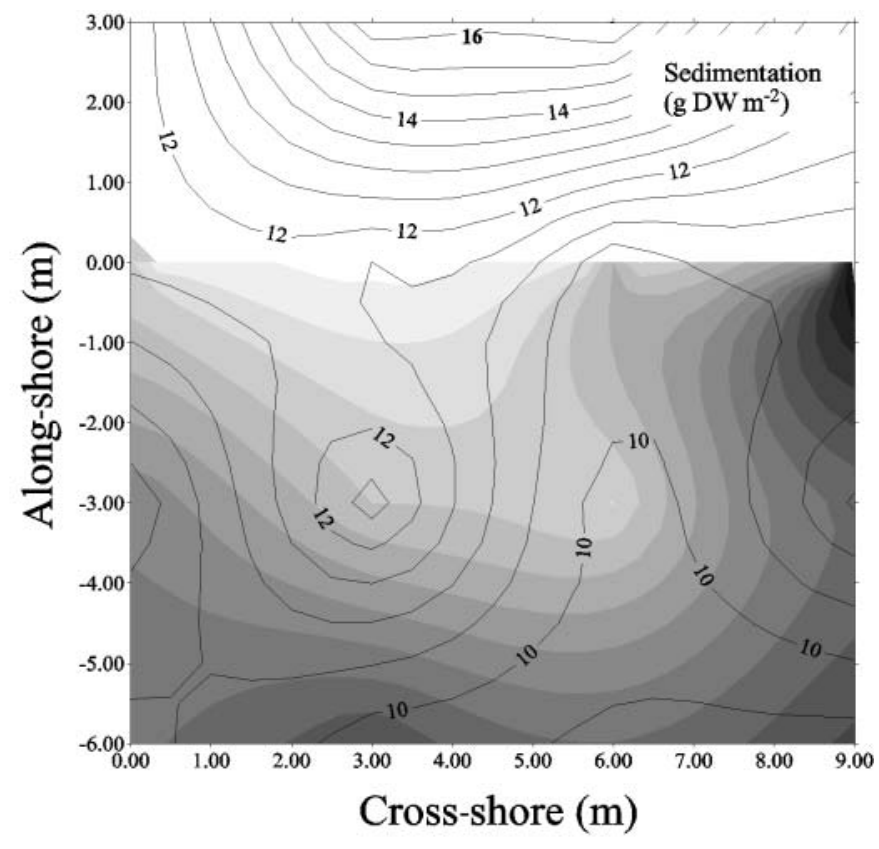

Fig. 12. Contour map of sedimented particles ( $g$ dry wt $\mathrm{m}^{-2}$ ) collected in sediment traps over a $3 \mathrm{~d}$ span from mid-day 2 June to mid-day 5 June

pattern of plants in a meadow has important implications for transport patterns in bottom boundary layers and that if eddy-viscosity models are used, drag is overestimated because shear stress is asymmetric below and above the meadow. Models should account for flow interactions between the inner and outer meadow, especially at the edge of meadows where fluctuations in the flow have very short time and length scales (Belcher \& Hunt 1998). Unfortunately, our maps were limited in spatial and temporal extent and hence in their usefulness for modelers. More extensive maps with finer vertical resolution need to be made over a longer duration to resolve the dynamics of the 3-D structure of the flow field in seagrass meadows. Nowell \& Jumars (1984) suggest distances equivalent to the thickness of 50 boundary layers from the edge of the meadow in order to measure the equilibrated flow. Assuming the boundary layer is equal to the nominal height of the plants $(60 \mathrm{~cm})$, the minimum distance would be $30 \mathrm{~m}$ into the meadow, which gives the reader an appreciation of how much more extensive a sampling grid is needed.

\section{Conclusions}

Maps and time-series of currents, wave velocities, and particle concentrations gave a synoptic view of fine-scale transport processes at a barren sand-meadow boundary. The horizontal structure of the meadow rerouted the mean flow, redistributing particles as a function of meadow architecture. The vertical flow modifications were linked to horizontal transport at the edge of the meadow where the plant density, which varied on the scale of meters, significantly altered the flow and the particle fields during low- and highenergy events. The overall reduction of vertical transport inside the meadow is in accordance with the lower particle concentrations and resuspension there. This fact confirms the importance of meadows in promoting sediment stability through the modification of the bottom boundary layer. The 3-dimensionality of the meadow acts as a bluff body diverting flow over the meadow, which is the path of least resistance, while producing a secondary circulation cell at the meadow's edge. Clearly, seagrass meadows are 3-D structures that produce complex, 3-D transport patterns.

Acknowledgements. The program 'Particle Dispersion in the Environment' was funded by the DGICYT (Dirección General de Investigación Científica y Tecnológica) of the Spanish government, grant HID97-0833 to the University of Girona. The CEAB (Centre d'Estudis Avançats de Blanes) study was funded by the project PhaSE (contract MAST-CT96-0053) of the European Commission. The manuscript is a contribution to the ELOISE program. We would like to thank all the PhaSE participants, especially F. Møhlenberg for providing pigment data and A. Stips for meteorological and current meter data. Wave data were provided by the Department for Technical Maritime Climate, National Ports of Spain. Special thanks go to Iolanda Abreu, captain of the 'Itxasbide', for her assistance during the meadow surveys. Lastly, we thank the 4 reviewers whose comments greatly improved the manuscript.

\section{LITERATURE CITED}

Ackerman JD, Okubo A (1993) Reduced mixing in a marine macrophyte canopy. Funct Ecol 7:305-309

Ambrose WGJ, Irlandi EA (1992) Height of attachment on seagrass leads to trade-off between growth and survival in the bay scallop Argopecten irradians. Mar Ecol Prog Ser 90:45-51

Belcher SE, Hunt JCR (1998) Turbulent flow over hills and waves. Annu Rev Fluid Mech 30:507-538

Boon JD, Green MO, Suh K (1998) Bimodal wave spectra in the lower Chesapeake Bay, sea bed energies and sediment transport during winter storms. Cont Shelf Res 16: 1965-1988

Chriss TM, Caldwell DR (1982) Evidence for the influence of form drag on bottom boundary layer flow. J Geophys Res 87:4148-4154

Dauby P, Bale AJ, Blommer N, Canon C, Ling RD, Norro A, Robertson RE, Simon A, Théate JM, Watson AJ, Frankignoulle M (1995) Particle flux over a Mediterranean seagrass bed: a one year case study. Mar Ecol Prog Ser 126: 233-246

Duarte CM, Benavent E, Sánchez MC (1999) The microcosm of particles within seagrass (Posidonia oceanica) canopies. Mar Ecol Prog Ser 181:289-295 
Eckman JE, Duggins DO, Sewell AT (1989) Ecology of understory kelp environments. I. Effects of kelps on flow and particle transport near the bottom. J Exp Mar Biol Ecol 129:173-187

Fegley SR, MacDonald BA, Jacobson TR (1992) Short-term variation in the quantity and quality of seston available to benthic suspension feeders. Estuar Coast Shelf Sci 34: 393-412

Fonseca MS, Cahalan JA (1992) A preliminary evaluation of wave attenuation by four species of seagrasses. Estuar Coast Shelf Sci 35:565-576

Fonseca MS, Fisher JS (1986) A comparison of canopy friction and sediment movement between four species of seagrass with reference to their ecology and restoration. Mar Ecol Prog Ser 29:15-22

Fonseca MS, Zieman JC, Thayer GW, Fisher JS (1983) The role of current velocity in structuring eelgrass (Zostera marina L.) meadows. Estuar Coast Shelf Sci 17: 367-380

Gacia E, Granata TC, Duarte CM (1999) An approach to measurement of particle flux and sediment retention within seagrass (Posidonia oceanica) meadows. Aquat Bot 65: $255-268$

Gambi MC, Nowell AR, Jamars PA (1990) Flume observations on flow dynamics in Zostera marina (eelgrass) beds. Mar Ecol Prog Ser 61:159-169

Gleason ML, Elmer DA, Pien NC, Fisher JS (1979) Effects of stem density upon sediment retention by salt marsh cord grass Spatina alterniflora Loisel. Estuaries 2:271-273

Grant WD, Madsen OS (1979) Combined wave and current interaction with a rough bottom. J Geophys Res 84: $1797-1808$

Grant WD, Williams AJ, Glenn SM (1984) Bottom stress estimates and their prediction on the northern California Continental Shelf during Code-1: the importance of windcurrent interaction. J Phys Oceanogr 14:506-527

Green MO, Black KP, Amos CL (1997) Control of estuarine sediment dynamics by interactions between currents and waves at several scales. Mar Geol 144:97-114

Grizzle RE, Short FT, Newell CR, Hoven H, Kindblom L (1996) Hydrodynamically induced synchronous waving of seagrasses: 'monami' and its possible effects on larval mussel settlement. J Exp Mar Biol Ecol 206:165-177

Gross TF, Isley AE, Sherwood CR (1992) Effective roughness changes during storms on the Northern California Shelf. Cont Shelf Res 12:389-419

Hawley N, Lesht BM (1992) Sediment resuspension in Lake St. Clair. Limnol Oceanogr 37:1720-1737

Irlandi EA, Peterson CH (1991) Modification of animal habitat by large plants: mechanisms by which seagrasses influence clam growth. Oecologia 87:307-318

Judge ML, Coen LD, Heck KL (1993) Does Mercenaria mercenaria encounter elevated food levels in seagrass beds? Results from a novel technique to collect suspended food resources. Mar Ecol Prog Ser 92:141-150

Koch EW (1996) Hydrodynamics of a shallow Thalassia testudinum bed in Florida, USA. In: Kuo J, Phillips R, Walker D, Kirkman H (eds) Proceedings of an International Workshop on Seagrass Biology, Rottnest Island, Australia, 25-29 January 1996. University of Western Australia Press, Nedlands, p 105-110

Koch EW (1999) Sediment resuspension in a shallow Tha- lassia testudinium banks ex. König bed. Aquat Bot 65: 269-280

Leonard LA, Luther ME (1995) Flow hydrodynamics in tidal marsh canopies. Limnol Oceangr 40:1474-1484

Lohrmann A, Cabrera R, Gelfenbaum G, Haines J (1995) Direct measurements of Reynolds stress with an acoustic Doppler velocimeter. In: Fundamentals and advancements in hydraulic measurements. Proceedings of the Hydraulic Divison of ASCE, 1-5 August, 1994, Buffalo, NY. American Society of Civil Engineers Press, Reston, VA, p 205-210

Lynch JF, Irish JD, Gross TF, Wiberg, PL, Newhall AE, Traykovski PA, Warren JD (1997) Acoustic measurements of the spatial and temporal structure of the near-bottom boundary layer in the 1990-1991 STRESS experiment. Cont Shelf Res 17:1271-1295

Nagata Y (1964) The statistical properties of orbital wave motions and their application for the measurement of directions wave spectra. J Oceanogr Soc Jpn 19:1-13

Nepf HM, Oldham C (1997) Exchange dynamics of a shallow contaminated wetland. Aquat Sci 59:193-213

Nepf HM, Sullivan JA, Zavistoski RA (1997) A model for diffusion within emergent vegetation. Limnol Oceanogr 42: 1735-1745

Nowell ARM, Jumars PA (1984) Flow environments of aquatic benthos. Annu Rev Ecol Syst 15:303-328

Oliver HR (1971) Wind profiles in and above a forest canopy. Q J R Meteorol Soc 97:548-553

Petersen JK, Scou O, Thor P (1997) In situ growth of the ascidian Ciona intestinalis (L.) and the blue mussel Mytilus edulis in an eelgrass meadow. J Exp Mar Biol Ecol 218: $1-11$

Peterson CH, Summerson HC, Duncan PB (1984) The influence of seagrass cover on population structure and individual growth rate of a suspension-feeding bivalve, Mercenaria mercemaria. J Mar Res 42:123-138

Rao KS, Wyngaard JC, Coté OR (1974) The structure of the two-dimensional internal boundary layer over a sudden change in surface roughness. J Atmos Sci 31:738-746

Reusch TB, Chapman AR (1995) Storm effects on eelgrass (Zostera marina L.) and blue mussel (Mytilus edulis L.) beds. J Exp Mar Biol Ecol 192:257-271

Schlüter L, Havskum H (1997) Phytoplankton pigments in relation to carbon content in phytoplankton communities. Mar Ecol Prog Ser 155:55-65

Shaw RH (1977) Secondary wind speed maxima inside plant canopies. J Appl Meteorol 16:514-521

Shaw RH, Silversides RH, Thurtell GW (1974) Some observations of turbulence and turbulent transport within and above plant canopies. Boundary-Layer Meteorol 5:429-449

Verduin JJ, Backhaus O (2000) Dynamics of plant-flow interactions for the seagrass Amphibolis antarctica: field observations and model simulations. Estuar Coast Shelf Sci 50: 185-204

Ward LG, Kemp WM, Boyton WR (1984) The influence of waves and seagrass communities on suspended particulates in an estuarine embayment. Mar Geol 59:85-103

Wolanski E, Chappell J, Ridd P, Vertessy R (1988) Fluidization of mud in estuaries. J Geophys Res 93:2351-2361

Wooding RA, Bradley EF, Marshall JK (1973) Drag due to regular arrays of roughness elements of varying geometry. Boundary-Layer Meteorol 5:285-308

Submitted: June 8, 2000; Accepted: August 24, 2000

Proofs received from author(s): July 26, 2001
Editorial responsibility: Otto Kinne (Editor),

Oldendorf/Luhe, Germany 